\title{
International Evidence On Purchasing Power Parity Theory: A Partial Equilibrium Empirical Investigation
}

Bahram Adrangi, University of Portland Mary Allender, University of Portland

Kambiz Raffiee, University of Nevada, Reno

\begin{abstract}
This paper tests the Purchasing Power Parity (PPP) theory in a partial equilibrium framework. Statistical tests are employed to test the PPP theory for floating exchange rates of the Australian and Canadian dollars, Swiss frank and the British pound. The study period spans the fourth quarter of 1974 through the fourth quarter of 2006. The Johansen and Juselieus test of cointegration supports a long-run relationship between inflation and exchange rate predicted by the PPP theory only for the bilateral exchange rates of the pound and the Australian dollar. This evidence suggests that the PPP in its strict theoretical sense in the case of the bilateral exchange rate of the US dollar and Australian dollar is rejected but not for the case of the exchange rate of the pound and US dollar. However, the Granger causality test further supports the findings of the cointegration test. It shows that in the short-run, the money supply and GDP ratios Granger cause the movements of this exchange rate.
\end{abstract}

\section{INTRODUCTION}

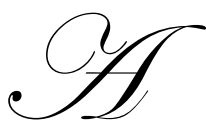

theory of exchange rate determination that has performed relatively well, at least in the long-run, is the purchasing power parity theory (PPP). The basic idea behind the PPP is the law of one price. It holds that prices of tradable goods would equalize in all markets once they are converted to the same currency. If not, there is an opportunity for arbitrage, which leads to adjustments in exchange rates until the law of one price is restored. Thus, in the most basic terms, the PPP links the exchange rates of currencies and the price of tradable goods in terms of various currencies. It also suggests an equilibrium value for currencies, which is the market exchange rate. The PPP has played a significant role in understanding exchange rate fluctuations. For instance, it has been employed to predict the equilibrium bilateral exchange rates between currencies based on the trends of consumer price indices or other measures of the general price levels.

Despite the theoretical soundness of the law of one price and the PPP, empirical findings have lent mixed support for the PPP. As was mentioned before, the law of one price is the basis for the validity of the PPP. However, for the law of one price to hold, most goods have to trade in frictionless markets. For instance, assuming that the transaction and transportation costs are already included in prices, if a pair of Nike athletic shoes costs sixty pounds in the U.K. and $\$ 120$ in the US, then the exchange rate of the pound will settle at two dollars. Otherwise, there will be arbitrage opportunities that will force the exchange rate toward the equilibrium rate of two dollars per pound. Empirical evidence supports PPP at the level of heavily traded commodities such as gold and crude oil, among others. (see Foot and Rogoff (1995), Hakkio (1992), Frankel and Rose (1995), Mac Donald and Taylor (1992))

As would be expected, the prediction power of the PPP diminishes as prices of broader baskets of tradable goods are considered. However, even at levels of aggregate prices, PPP offers relatively reliable predictions of exchange rate movements in the long-run. For instance it predicts that currencies of the economies with higher inflation rates than their trading partners would tend to depreciate over time. 
A survey of the literature on the law of one price (LOP) implies that the magnitude of discrepancies in prices are large, the speed of adjustment slow, and arbitrage processes that could potentially restore the exchange rate adjustment are imperfect. For instance, Isard (1977), Richardson (1978), Giovannini (1988), among others have shown that the deviations of prices from the LOP are large, persistent and correlated with exchange rate movements. Engel and Rogers (1995) and Engel (1993) show that price volatilities within the same country and across borders are not consistent with the LOP.

The limitations of the LOP in stimulating effective arbitrage in international markets even for homogenous goods, may be one of the reasons why tests of PPP based on price indices produce disappointing results regarding the validity of the PPP. For instance, Huizinga (1987) and Meese and Rogoff (1988) fail to reject the hypothesis that exchange rates follow a random walk process. Frankel (1990) argues that if exchange rate deviations from PPP dampen slowly, it will be difficult to statistically or otherwise observe the convergence to rates justified by the PPP. Using a data set spanning 1869-1984 for dollar/pound exchange rates, he was able to reject the random walk hypothesis for this exchange rate series.

More recent studies have applied cointegration tests to test for PPP. For instance, Bahmani-Oskooee and Goswami (2005) show that while the model variables are cointegrated in a Johansen-Juselius framework, the domestic price and the foreign price are not weakly exogenous in many countries, and because of that a direct test provides the rejection of the PPP hypothesis.

Other studies, using unit root or cointegration tests investigate mean reversion or long-run equilibrium relationships in the context of PPP have produced mixed results. Notably, Simmons and Aggarwal (2005), Narayan (2005), Chowdhry, Roll and Xia (2005), among others.

Our paper takes a new approach. Rather than testing mean reversion, or speed of adjustment toward the equilibrium exchange rate as suggested by the PPP, we introduce a partial equilibrium theoretical model to test the PPP theory. We employ regression analysis in conjunction with Johansen and Juselieus cointegration tests to arrive at our empirical findings.

Our findings show that the PPP hypothesis in its strict theoretical sense in the case of the bilateral exchange rate of the US and Australian dollars is rejected. The restriction of unitary elasticity of money and GDP for the British pound cannot be rejected. Thus, in the case of the bilateral exchange rate of the pound and US dollar the strict PPP theory may be supported by the empirical evidence.

Cointegration and the Granger causality tests between the money supply and GDP ratios and the exchange rate of the Australian dollar show that, while the PPP cannot be strictly established, a relationship between the exchange rate and the money supply and GDP variables, suggested by the theoretical model, has been verified in the long- and short-run by cointegration and the Granger causality tests, respectively.

The Granger causality test fails to show a short-run causality between the bilateral money supply and GDP ratios of the US and UK and the pound as predicted by the theoretical model presented in this paper. Thus, the short- run fluctuations of the pound may be more a result of interest rate differentials between the US and the UK rather than money supply and GDP variables. The impulse response analyses based on the vector moving average models support these statistical findings.

Section II offers a theoretical model as the framework of our empirical tests. Section III briefly discusses our variables, the data and their source, and the empirical methodology of the paper. We present and analyze our empirical findings in Section IV. Section V offers a summary and analysis of our findings.

\section{THE THEORETICAL MODEL}

To build a theoretical framework that guides us through the empirical investigation, we combine the absolute version of the PPP with the modern monetary theory. The motivation for this approach is that as the 
modern monetary theory holds, prices and their fluctuations are a monetary phenomenon. Indeed, without the use of money, price levels and inflation would be hard to measure or even meaningless. We begin with the absolute PPP proposition that the exchange rate between two currencies is determined by the relative levels of general prices in two economies. For instance, considering the direct exchange rate of the Canadian dollar (C\$) in terms of the U.S. dollars, we have the following

$\mathrm{C} \$=\mathrm{Pus} / \mathrm{Pca}$,

Where Pus and Pca represent price indices in the US and Canada, respectively.

The modern monetary theory which employs the classical quantity theory of money, links price levels with money supply, and national income levels. According to the quantity theory of money we have the following relationship:

$\mathrm{MV}=\mathrm{PY}$,

where $\mathrm{M}$ is the a measure of monetary aggregate such as M1, V is the velocity of money, which is assumed to be fairly stable over time, and P shows the aggregate price level, and Y represents the level of national income. Thus, the aggregate price levels for Canada and the U.S. may be computed from equation (2) and substituted in equation (1).

Pus= MusVus/Yus

$\mathrm{Pca}=\mathrm{Mca} \mathrm{Vca} / \mathrm{Yca}$.

Substituting equation (3) into equation (1) results in equation (4).

$\mathrm{C} \$=(\mathrm{Mus} / \mathrm{Mca}) .(\mathrm{Vus} / \mathrm{Vca}) .(\mathrm{Yca} / \mathrm{Yus})$.

Taking the logarithms of both sides produces the testable function that shows the relationship between exchange rates, money supply, and GDP in various economies.

LnC\$= Ln(Mus/Mca)+ Ln (Vus/Vca) +Ln(Yca/Yus).

Furthermore, equations (4) and (5) show that the bilateral exchange rate of the Canadian dollar is directly related to the stock of US money supply, and inversely related with the US GDP. For instance as the US money supply rises, the dollar price of the Canadian dollar rises as well. Furthermore, rising Canadian GDP is correlated with rising value of the Canadian dollar in terms of the US dollar. Both of these relationships are plausible. Rising money supply of the US may trigger higher inflation in the US, assuming that the real GDP is not rapidly responding to increases in the money supply. Higher US inflation would imply a lower value for the US dollar in international currency markets.

The rising Canadian GDP relative to the US GDP would instigate two opposite reactions. First, it may stimulate more demand for the US dollar by Canadian consumers and importers, thus, strengthening the US dollar, and potentially reducing the exchange rate of the Canadian dollar. On the other hand as the GDP in Canada increases, transactions demand for Canadian dollar also increases, raising the value of the Canadian dollar. The result of this tug of war between two effects may be examined empirically.

\section{METHODOLOGY}

The main econometric tool used in this paper is the vector autoregressive technique (VAR). A VAR consists of a system of dynamic simultaneous Equations. In each Equation, an endogenous variable is a function of exogenous as well as the lagged values of all endogenous variables. Thus, a VAR allows for the simultaneous and dynamic interaction of all endogenous variables. More importantly, a VAR provides an unrestricted approximation 
to the reduced form of an unknown structural system of simultaneous Equations. Though the underlying structure is not specified, it is assumed to exist.

A VAR model serves as a flexible approximation to the reduced form of any wide variety of simultaneous structural models. This system of Equations can be written in compact matrix notation as follows:

$$
\left[\begin{array}{lll}
1-\alpha_{11}(L) & -\alpha_{12}(L) & -\alpha_{13}(L) \\
-\alpha_{21}(L) & 1-\alpha_{22}(L) & -\alpha_{23} \\
-\alpha_{31}(L) & -\alpha_{32}(L) & 1-\alpha_{33}(L)
\end{array}\right]\left[\begin{array}{l}
E X_{t} \\
M U S / M f_{t} \\
Y f / Y u s_{t}
\end{array}\right]+\left[\begin{array}{l}
\beta_{1} \\
\beta_{2} \\
\beta_{3}
\end{array}\right]=\left[\begin{array}{l}
u_{1 t} \\
u_{2 t} \\
u_{3 t}
\end{array}\right]
$$

where $\alpha_{11}(L)$ through $\alpha_{22}(L)$ are n-th order scalar polynomials in the lag operator $\mathrm{L}$, where $\alpha_{i j}(L)=$ $\sum_{k=1}^{m} a_{i j} L^{k}$, and $L^{k} \mathrm{x}_{t}=\mathrm{x}_{t-k}$, and $\mathrm{m}$ is the lag length specified. Variables $\mathrm{EX}_{t}, \mathrm{Mus} / \mathrm{Mf}_{t}, \mathrm{Yf} / \mathrm{Yus}$ represent the bilateral exchange rate, ratio of money supply for the two economies, and GDP ratio, respectively, $\beta_{i}$, model constants, and $u_{t}=\left[u_{1 t} u_{2 t}\right]$ is a vector of white noise residuals process.

VAR models are routinely used to perform impulse response analysis, which allow us to measure the various period impact of the $u_{t-i}$ on each variable. Impulse response analysis requires a vector moving average (VMA) representation of a VAR. The VMA allows us to trace out the time path of the various shocks on the variables of the VAR system. Consider the VMA process given by

$$
\left[\begin{array}{l}
E X_{t} \\
M u s / M f_{t} \\
Y f / Y_{t}
\end{array}\right]=\left[\begin{array}{l}
E \bar{X} \\
M u s / M \bar{f} \\
Y f / Y u \bar{s}
\end{array}\right]+\left[\begin{array}{lll}
\phi_{11}(i) & \phi_{12}(i) & \phi_{12}(i) \\
\phi_{21}(i) & \phi_{22}(i) & \phi_{22}(i) \\
\phi_{31}(i) & \phi_{32}(i) & \phi_{33}(i)
\end{array}\right]\left[\begin{array}{l}
\varepsilon_{E X t-i} \\
\varepsilon_{M u s / M f t-i} \\
Y f / Y u s_{t-i}
\end{array}\right] .
$$

The sets of coefficients $\phi_{k j}(i)$ are called the impulse response functions. For example $\phi_{12}(0)$ is the instantaneous impact of a one-unit change in $\varepsilon_{M u s / M f t}$ on EXt ${ }_{t}$. Similarly, $\phi_{12}(1)$ is the one period response of $\mathrm{EX}_{t}$ to one unit change in $\varepsilon_{M u s / M f t-1}$. The accumulated effect of unit impulses in $\varepsilon_{M u s / M f t}$ on $\mathrm{EX}_{t}$ for example, can be computed by summing the coefficients of the impulse response function. Thus, the effect of $\varepsilon_{M u s / M f t}$ on the $\mathrm{EX}_{t}$ after $\mathrm{n}$ periods is given by

$\sum_{i=0}^{n} \phi_{12}(i)$

To produce reliable VAR estimates and impulse response analysis, variables of the model are required to be stationary, i.e., not have unit roots. 


\section{a. Unit Root Tests}

The ADF (Dickey and Fuller (1979)) and PP (Phillips and Perron (1988)) tests of unit roots are used in the present study. The ADF entails estimating $\Delta \mathrm{x}_{t}=\alpha+\beta \mathrm{x}_{t-1}+$

$\sum_{j=1}^{L} \gamma_{j} \Delta \mathrm{x}_{t-j}+u_{t}$ and testing the null hypothesis that $\beta=0$ versus the alternative of $\beta<0$, for any $\mathrm{x}$. The lag length $\mathrm{j}$ in the ADF test regressions are determined by the Akaike Information Criterion (AIC). The PP test estimates $\Delta \mathrm{x}_{t}=\alpha+\beta \mathrm{x}_{t-1}+u_{t}$ and tests the null hypothesis that $\beta=0$ versus the alternative of $\beta<0$. Three

variations of the ADF and PP regressions are estimated: with intercept, trend and intercept, and neither trend nor intercept. The purpose of this approach is to insure that the test results are robust in the presence of drifts and trends. The PP test may be more appropriate if autocorrelation in the series under investigation is suspected. The statistics are transformed to remove the effects of autocorrelation from the asymptotic distribution of the test statistic. The formula for the transformed test statistic is given in Perron (1988). The lag truncation of the Bartlett Kernel in the PP test is determined by Newey and West (1987). In both the ADF and PP tests the MacKinnon (1990) critical values are used. Accepting the null hypothesis means that the series under consideration is not stationary and a unit root is present.

\section{b. Cointegration Tests And Long-Run Equilibrium}

We also test for the long-run equilibrium relationship among the variables employing Johansen and Juselius (1990) cointegration test. Cointegration refers to the possibility that non-stationary variables may have a linear combination that is stationary. Such a linear combination, the cointegrating vector, implies that there is a long-run equilibrium relationship among variables, i.e., variables will not wander off apart from one another over extended periods of time. Therefore, cointegration between the stock index, price levels, and interest rates implies a long-run relationship between these variables. The test of cointegration employed in this paper, Johansen (1988) and Johansen and Juselius (1990) methodology, is a multivariate generalization of the methodology suggested by Engle and Granger (1987). A brief description of the test is as follows. Let

$\Delta \mathrm{x}_{t}=\sum_{i=1}^{p-1} \Gamma_{i} \Delta x_{t-i}+\pi \mathrm{x}_{t-1}+\varepsilon_{t}$

where $\mathrm{x}_{t}$ and $\varepsilon_{t}$ are $\left(\mathrm{n}_{*} 1\right)$ vectors and $\pi$ is an $\left(\mathrm{n}_{* \mathrm{n}} \mathrm{n}\right)$ matrix of parameters. The Johansen (1988) methodology requires estimating the system of Equations in (9) and examining the rank of matrix $\pi$. If rank $(\pi)=0$, then there is no stationary linear combination of the $\left\{\mathrm{x}_{i t}\right\}$ process, the variables are not cointegrated. Since the rank of a matrix is the number of non-zero eigenvalues $(\lambda)$, the number of $\lambda>0$ represents the number of cointegrating vectors among the variables. The test for the non-zero eigenvalues is normally conducted using the following two test statistics:

$\lambda_{\text {trace }}(\mathrm{r})=-\mathrm{T} \sum_{i=r+1}^{n} \ln \left(1-\hat{\lambda}_{i}\right)$
$\lambda_{\max }(\mathrm{r}, \mathrm{r}+1)=-\mathrm{T} \ln \left(1-\hat{\lambda}_{r+1}\right)$

where $\hat{\lambda}_{i}$ is the estimated eigenvalues, and $\mathrm{T}$ is the number of valid observations. Note that $\lambda_{\text {trace }}$ statistic is simply the sum of $\lambda_{\max }$ statistic. In Equation (13), $\lambda_{\text {trace }}$ tests the null hypothesis that the number of distinct cointegrating vectors is less than or equal to $r$ against a general alternative. $\lambda_{\max }$ statistic tests the null hypothesis 
of $r$ cointegrating vectors against $r+1$ cointegrating vectors. Johansen and Juselius (1990) and Osterwal- Lenum (1992) derive the critical values of $\lambda_{\text {trace }}$ and $\lambda_{\max }$ by simulation method.

\section{DATA AND EMPIRICAL FINDINGS}

The data for the countries under consideration are taken from the International Financial Statistics of International Monetary Fund. It consists of floating exchange rates of the Australian and Canadian dollars (A $\$$ and $\mathrm{C} \$$ respectively), the Swiss frank (SF), the British pound (£), and quarterly M1 money supply as well as GDP for the nations under consideration. The period of the study covers 1974 through the fourth quarter of 2006. In some cases shorter time series are available.

Table 1 provides the summary statistics on bilateral exchange rates, money supply ratios, as well as GDP ratios for the currencies under study. The ADF, PP, and KPSS tests of stationarity indicate that some variables may not be stationary. Notably, exchange rates of currencies under consideration are non-stationary, i.e., not mean reverting as the PPP theory would predict.

While exchange rates are not mean-reverting as suggested by the PPP theory, the model proposed in equation (5) suggests that based on the PPP, exchange rates, relative money supplies and the relative GDPs are correlated. In order to investigate the validity of the equation (5) regressions have to be estimated. However, because of the non-stationary variables involved in regressions, the estimation results may be spurious. Therefore, variable transformation may be required.

To continue with our empirical tests, it may be appropriate to consider cointegration tests prior to any regression estimation. The objective is to find out if bilateral exchange rates of the US dollar are cointegrated with money supply ratios and GDP ratios in equation (5). If so, we would conclude that model variables exhibit a longrun equilibrium relationship.

Johansen and Juselius cointegration test under five assumptions regarding the data trend, intercept, and trend in the cointegrating vectors. Results show that in two out of four cases there is at least one cointegrating vector among exchange rates, money supply and GDP ratios. In the case of the Canadian dollar and the Swiss francs, there are no cointegrating vectors. This finding suggests that there are no long- run equilibrium relationships between the exchange rate of the dollar and ratios of money supply and GDP of these countries and the US. In the absence of such a long -run relationship, one would expect that the tests of PPP theory would fail to produce the results predicted by the theory. Thus, the remainder of the empirical investigation is reported for the Australian dollar and the British pound.

Variables in equation (5) are expressed in logarithms. Thus, logarithm of variables are tested for stationarity. It is shown that the majority of the variables in equation (5) are nonstationary. Thus, we do not estimate regression equation (5) as the results may be spurious. To examine the long-run equilibrium relationship among the variables of equation (5) we test for cointegration among these variables.

In order to perform the cointegration tests and estimate the long-run equilibrium relationship among the model variables in the bilateral framework, the proper order of the vector autoregressive models (VAR) have to be estimated.

To accomplish this task, VAR models of order six for the Australian dollar and the British pound are estimated. The justification for choosing a lag order of six is that the effects of change in money supply and variations of the GDP may filter through the economy with a maximum lag of around six quarters. Most economists believe that approximately three quarters are necessary for the full effects of monetary policy to take hold.

Having estimated the VAR model of order six for the two currencies, the modified loglikelihood ratio test, the final prediction error (FPE), Akaike Information Criteron (AIC), Schwarz Infrmation Criterion (SIC), and the Hannan-QuinnInformation Criterion (HQ) are employed to statistically determine the VAR order. The minimum 
FPE, AIC, SC, and HQ as well as statistically significant value of the LR test indicate that the optimum VAR lag order is one for the Australian dollar. For the case of the bilateral exchange rate of the British pound (pound) various tests of lag order selection provide conflicting VAR orders. Therefore, several VARs with the above lag orders were estimated. The portmanteau test of the VAR residuals showed that the most appropriate lag order is two.

Table 2 provides the maximum eigenvalue and trace statistics for cointegration. Both eigenvalue and trace tests show that there is one cointegrating vector in cases of Australian dollars and the pound. Therefore, it is expected that these exchange rates of these currencies, money supply and price levels will show a long-run equilibrium relationship.

For the case of the Australian dollar and the British pound VAR models of order one and two, respectively, are estimated. To ensure that the VAR estimation results are not biased and that the VAR order is appropriate, the portmanteau residual autocorrelation test is conducted as a part of the post estimation tests. The portamanteau test of residual autocorrelation shows that the residuals are free of autocorrelation as shown by the Q statistic in both cases.

Having estimated the VAR models for the pound and the Australian dollar, two error correction models are obtained. The estimated error correction model for the Australian dollar shows an error correction term that is statistically significant but has the wrong sign. The magnitude of the coefficient $(0.022)$ is small suggesting that the shocks to the Australian dollar may result in the currency moving away from its equilibrium value, however, quite slowly.

The error correction model for the pound shows that the error correction variable exhibits the expected sign and is statistically significant. Therefore, it is evident that whenever the pound exchange rate is out of equilibrium in this model, it eventually returns to its equilibrium after shocks to the money market and the GDP, albeit slowly. These findings are shown in Table 3

To examine the validity of the strict PPP hypothesis for the Australian dollar, we test the restrictions that the long-run elasticities of the money supply and the GDP variables in the cointegrating equation are equal to one. The value of the chi-squared statistic for these restrictions is 19.50 , which shows that the restrictions that the elasticities of GDP and the money supply are one are rejected with certainty. This evidence suggests that the PPP in its strict theoretical sense in the case of the bilateral exchange rates of the US and Australian dollars is rejected

The restriction of unitary elasticity of money and GDP for the British pound cannot be rejected as shown by the insignificance of the chi-squared statistic. The implication is that in the case of the bilateral exchange rate of pound and US dollar the strict PPP may not be rejected. Table 4 reports these findings.

Recognizing that there is a long-run bilateral relationship between the Australian dollar and the ratios of money supply and GDP for the Australian dollar, we move to test the Granger causality between the money supply and GDP on the one hand and the Australian dollar on the other. These results are reported in Table 5. The Wald test rejects the lack of Granger causality and further bolsters the previous findings that the money supply and GDP ratios for the Australian dollar Granger cause the movements of the currency. Thus, in the case of the Australian dollar, while the PPP cannot be strictly established, a relationship between the exchange rate and the money supply and GDP variables, suggested by the theoretical model, has been verified in the long- and short-run by cointegration and Granger causality tests.

The Granger causality test fails to show a causality between the bilateral money supply and GDP ratios of the US and UK and the pound. This finding shows that despite a long- run equilibrium among the model variables as predicted by the PPP theory, the short-run causality does not exist. Thus, the short- run fluctuations of the pound may be more a result of interest rate differentials between the US and the UK rather than money supply and GDP variables. 
Comparing the statistical findings regarding exchange rates of the Australian dollars and the British pound, we conclude that structural similarities between the US and the British economies, and extent of the free trade flow between the two countries, as well as the size of British investments in the US economy, contribute to the alignment of the two currencies as predicted by the PPP theory.

\section{Impulse Response Analysis}

Impulse response analysis shows that after reacting to a one standard deviation shock, the Australian dollar returns to its original level in a few periods. However, shocks to the money supply and the GDP variable have a long run effect on the exchange rate. For instance, a one standard deviation shock to the money supply variable, permanently alters the path of the Australian dollar, though the currency settles at a new and steady path. A one standard deviation shock to GDP on the other hand, generates a new path for the currency which shows no settling down. This might reinforce the conclusion that the error correction term was significant statistically, but exhibited the wrong sign, alluding to an explosive path for the currency. These are shown in panel A, the first graph in Figure 1. The bottom two graphs demonstrate the effects of shocks to the exchange rates on the money supply and the GDP variables. The focus of our paper, however, has been the behavior and responses of exchange rates to the remaining variables of the model, and these results are tangential to the objective of this paper.

The Impulse response for the pound offers a different picture than the one for the Australian dollar. It shows that the shocks to GDP in the long run contribute to a new equilibrium level of the pound. However, the arrival of the pound at the new equilibrium level is fairly rapid. The same is not true of the pound response to a one standard deviation shock to the money supply. The pound tends to diverge from its equilibrium level and not return to a new equilibrium level. This suggests the importance of the role of the monetary policy on the exchange rate. It further seems to lend support for the PPP theory in the sense that the shocks to the money supply probably contribute to inflationary pressures. The inflationary shocks are shown to have a long-run deleterious effect on the exchange rate of the pound instigating a protracted decline in the exchange rate.

\section{SUMMARY AND CONCLUSIONS}

This paper tests the Purchasing Power Parity (PPP) theory in a partial equilibrium framework. Statistical tests are employed to test the PPP theory for the exchange rates of the Australian and Canadian dollars, Swiss frank and the British pound. The period of the study spans the fourth quarter of 1974 through the fourth quarter of 2006.

The ADF, PP, and KPSS tests of stationarity indicate that exchange rates are not mean-reverting as suggested by the PPP theory. However, the theoretical model of the paper suggests that based on the PPP, exchange rates, relative money supplies and the relative GDPs are correlated. The Johansen and Juselius test of cointegration supports a long-run relationship between inflation and exchange rates predicted by the PPP only for the bilateral exchange rate of the pound and the Australian dollar.

To examine the validity of the strict PPP hypothesis for the Australian dollar, we test the restrictions that the long-run elasticities of the money supply and the GDP variables in the error-correction equations are equal to one. The evidence suggests that the PPP in its strict theoretical sense in the case of the bilateral exchange rate of the US and Australian dollars is rejected.

The restriction of unitary elasticity of money and GDP for the British pound cannot be rejected. The implication is that in the case of the bilateral exchange rate of the pound and US dollar the strict PPP theory may be supported by the empirical evidence.

Recognizing that there is a long-run bilateral relationship between the Australian dollar and the ratios of money supply and GDP for the Australian dollar, we employ the Granger causality test between the money supply and GDP ratios and the exchange rate of the Australian dollar and the British Pound. We find that in the case of the Australian dollar, while the PPP cannot be strictly established, a relationship between the exchange rate and the money supply and GDP variables, suggested by the theoretical model, has been verified in the long- and short-run by cointegration and the Granger causality tests, respectively. 
While the PPP theory in the long-run is supported for the exchange rate of the pound and dollar, the Granger causality test fails to show a short-run causality between the bilateral money supply and GDP ratios of the US and UK and the pound as predicted by the theoretical model presented in this paper. Thus, the short- run fluctuations of the pound may be more a result of interest rate differentials between the US and the UK rather than money supply and GDP variables. The impulse response analyses based on the vector moving average models support these statistical findings.

\section{REFERENCES}

1. Akaike, H. (1974). A New Look at Statistical Model Identification, IEEE Transactions on Automatic Control, 19, 716-723.

2. Bahmani-Oskooee, Mohsen, G., Goswami, (2005). Black Market Exchange Rates and Purchasing Power Parity in Emerging Economies, Emerging Markets Finance and Trade, v41, n3 (37-52.

3. Chowdhry, Bhagwan, R. Roll, Y. Xia, (2005) Extracting Inflation from Stock Returns to Test Purchasing Power Parity, American Economic Review, v95, n1, 255-76.

4. Dickey, D.A. and A. W. Fuller. (1979). Distribution of the Estimators for Autoregressive Time series with a Unit Root, Journal of the American Statistical Association, 1057-1072.

5. Engel, Charles, J. H. Rogers, (1995). Regional Patterns in the Law of One Price: The Roles of Geography vs. Currencies, National Bureau of Economic Research, Inc, NBER Working Papers: 5395.

6. Engel, Charles, (1993). Violating the Law of One Price: Should We Make a Federal Case Out of It? National Bureau of Economic Research, Inc, NBER Working Papers: 7242.

7. Engle, R. F. and C. W. J. Granger. (1987). Co-integration and Error-Correction: Representation, Estimation, and Testing, Econometrica, 315-329.

8. Froot, Kenneth A. and K. Rogoff, (1995). Perspectives on PPP and Long-Run Real Exchange Rates, National Bureau of Economic Research, Inc, NBER Working Papers: 4952, 1996.

9. Frankel, Jeffrey A., A. K. Rose, (1995). A Panel Project on Purchasing Power Parity: Mean Reversion Within and Between Countries, National Bureau of Economic Research, Inc, NBER Working Papers: 5006.

10. Giovannini, Alberto, (1988). Exchange Rates and Traded Goods Prices, Journal of International Economics, v24, n1/2 (45-68.

11. Hakkio, Craig S., (1992). Is Purchasing Power Parity a Useful Guide to the Dollar?"= Federal Reserve Bank of Kansas City Economic Review, v77, n3 37-51.

12. Huizinga, John, (1987). An Empirical Investigation of the Long-run Behavior of Real Exchange Rates, Carnegie-Rochester Conference Series on Public Policy v27, 149-214.

13. Isard, Peter, (1976). How far can we push the 'law of one price'? Board of Governors of the Federal Reserve System (U.S.), International Finance Discussion Papers, 84.

14. Johansen, S. (1988). Statistical Analysis of Cointegration Vectors, Journal of Economic Dynamics and Control, 12, 231-54.

15. Johansen, S. and K. Juselius (1990). Maximum Likelihood Estimation and Inference on CointegrationWith Applications to Demand for Money, Oxford Bulletin of Economics and Statistics, 52, 169-210.

16. Meese, Richard A. and K. Rogoff, K (1988). Was It Real? The Exchange Rate-Interest Differential Relation over the Modern Floating-Rate Period, Journal of Finance v43, n4, 933-48.

17. Narayan, Paresh Kumar, (2005). New Evidence on Purchasing Power Parity from 17 OECD Countries, Applied Economics, v 37, n9, 1063-71.

18. Newey, W. K., and K. West (1987). A Simple Positive-Definite Heteroscedasticity and Autocorrelation Consistent Covariance Matrix, Econometrica, 55, 703-708.

19. Osterwald-Lenum, M. (1992). A Note with Quintiles of the Asymptotic Distribution of the Maximum Likelihood Cointegration Rank Test Statistics, Oxford Bulletin of Economics and Statistics, 54, pp. 461471.

20. Perron, P.(1988). Trends and Random Walks in Macroeconomic Time Series, Journal of Economic Dynamics and Control, 12, 297-332.

21. Phillips, P.C.B. and P. Perron (1988). Testing for a Unit Root in Time Series Regression, Biometrika, 75, 335-346. 
22. Richardson, J. David, (1978). Some Empirical Evidence on Commodity Arbitrage and the Law of One Price, Journal of International Economics, v8, n2, 341-51.

23. Simmons, Walter, R. Aggarwal, (2005). Purchasing Power Parity in the Eastern Caribbean Currency Union, Journal of Developing Areas, v38, n2, 155-69.

Table 1 Summary Statistics

\begin{tabular}{|c|c|c|c|c|c|c|}
\hline & $\mathrm{A} \$$ & $\mathrm{C} \$$ & SF & $£$ & $\mathrm{M}_{\mathrm{us}} / \mathrm{M}_{\mathrm{a}}$ & $\mathrm{M}_{\mathrm{us}} / \mathrm{M}_{\mathrm{ca}}$ \\
\hline Mean & 80.48 & 94.26 & 165.79 & 108.72 & 0.62 & 0.76 \\
\hline Std Dev. & 20.09 & 10.02 & 35.20 & 17.69 & 0.23 & 0.21 \\
\hline Sk & 0.041 & -0.056 & -0.165 & 0.87 & -0.291 & -0.39 \\
\hline Kurt & 2.000 & 1.879 & 2.245 & 3.261 & 1.75 & 2.04 \\
\hline $\mathrm{JB}$ & 5.39 & $6.82^{* *}$ & 3.22 & $15.10^{* * *}$ & $8.88^{* * *}$ & $7.47^{* *}$ \\
\hline $\mathrm{ADF}$ & -1.858 & -1.872 & -2.399 & -2.89 & -1.55 & -1.73 \\
\hline $\mathrm{PP}$ & -2.00 & -1.897 & -2.47 & -2.56 & -2.15 & -2.01 \\
\hline KpssLM & $0.20^{*}$ & $0.123^{*}$ & $0.135^{*}$ & 0.116 & $0.19^{*}$ & $0.12^{*}$ \\
\hline
\end{tabular}

Table 1

Summary Statistics Cont'd

\begin{tabular}{|c|c|c|c|c|c|c|}
\hline & $\mathrm{M}_{\mathrm{us}} / \mathrm{M}_{\mathrm{sw}}$ & $\mathrm{M}_{\mathrm{us}} / \mathrm{M}_{\mathrm{uk}}$ & $\mathrm{Y}_{\mathrm{a}} / \mathrm{Yu}_{\mathrm{s}}$ & $\mathrm{Y}_{\mathrm{ca}} / \mathrm{Y}_{\text {us }}$ & $\mathrm{Y}_{\mathrm{sw}} / \mathrm{Y}_{\mathrm{us}}$ & $\mathrm{Y}_{\mathrm{uk}} / \mathrm{Y}_{\mathrm{us}}$ \\
\hline Mean & 1.65 & 2.25 & 0.96 & 0.99 & 0.79 & 0.87 \\
\hline Std Dev. & 0.43 & 7.27 & 0.023 & 0.039 & 0.10 & 0.06 \\
\hline Sk & 0.69 & -0.64 & 0.64 & -0.38 & -0.006 & 0.90 \\
\hline Kurt & 2.26 & 34.37 & 2.63 & 1.65 & 2.11 & 3.26 \\
\hline JB & $11.86^{* *}$ & $4764 * * *$ & $8.64 * * *$ & $11.59 * * *$ & 3.71 & $16.08 * * *$ \\
\hline $\mathrm{ADF}$ & -0.46 & $-10.13 * * *$ & -2.38 & -1.59 & $-3.46 * *$ & $-3.23^{*}$ \\
\hline PP & -0.56 & $-10.13 * * *$ & -2.38 & -1.98 & $-3.16^{*}$ & -2.15 \\
\hline KpssLM & $0.23 * * *$ & 0.069 & $0.22 * * *$ & 0.12 & 0.08 & $0.214 * *$ \\
\hline
\end{tabular}


Table 2

Cointegration with unrestricted intercepts and no trends in the VAR Cointegration LR Test Based on Maximal Eigenvalue of the Stochastic Matrix

\begin{tabular}{lccc} 
& & Australia & UK \\
& & & $\lambda_{\max }$ \\
Null & Alternative & $\lambda_{\max }$ & 21.217 \\
$\mathrm{r}=0$ & $\mathrm{r}=1$ & $24.716^{* *}$ & 7.990 \\
$\mathrm{r}<=1$ & $\mathrm{r}=2$ & 8.716 & 6.944 \\
$\mathrm{r}<=2$ & $\mathrm{r}=3$ & 0.279 & \\
\hline
\end{tabular}

Cointegration LR Test Based on Trace of the Stochastic Matrix

\begin{tabular}{lccc} 
& & Australia & UK \\
\hline Null & Alternative & $\lambda_{\text {trace }}$ & $\lambda_{\text {trace }}$ \\
$\mathrm{r}=0$ & $\mathrm{r}>=1$ & 33.712 & 36.151 \\
$\mathrm{r}<=1$ & $\mathrm{r}>=2$ & 8.9961 & 14.934 \\
$\mathrm{r}<=2$ & $\mathrm{r}=3$ & 0.279 & 6.944 \\
\hline
\end{tabular}

Notes: Cointegration with unrestricted intercepts and no trends in the VAR

Australia: Order of VAR $=1$. UK: Order of $\mathrm{VAR}=2$.

Table 3

OLS estimation of Error Correction Models of Australian and British Currency Rates

Panel a: Australian Dollar

Dependent variable is dLNAEX

\begin{tabular}{lllllll}
\hline Regressor & Coefficient & Standard Error & T-Ratio & $\mathrm{R}^{2}$ & $\mathrm{~F}$ & $\mathrm{DW}$ \\
Intercept & -0.072 & 0.0719 & -1.00 & 0.008 & 0.92 & 2.08 \\
ecm1(-1) & 0.016 & 0.0170 & 0.954 & & & \\
\hline
\end{tabular}

ECM for variable LNAEX estimated by OLS based on cointegrating VAR(1)

dLNAEX = LNAEX-LNAEX $(-1)$

ecm $1=1.0000 *$ LNAEX $+8.6977 *$ LNYA_US -.059970*LNMUS_MA

Panel b: British Pound

Dependent variable is dLNUEX

\begin{tabular}{lllllll}
\hline & & & & & DW \\
Regressor & Coefficient & Standard Error & T-Ratio & $\mathrm{R}^{2}$ & F & 1.99 \\
Intercept & 0.106 & 0.043 & 2.436 & 0.12 & 3.58 & \\
dLNUEX1 & 0.215 & 0.092 & 2.335 & & & \\
dLNYUS_US1 & 0.454 & 0.282 & 1.611 & & \\
dLNMUS_MU1 & 0.012 & 0.006 & 1.914 & & \\
ecm1(-1) & -0.021 & 0.0086 & -2.494 & & \\
\hline
\end{tabular}

ECM for variable LNUEX estimated by OLS based on cointegrating VAR(2)

List of additional temporary variables created: dLNUEX = LNUEX-LNUEX(-1), dLNUEX1 = LNUEX(-1)-LNUEX(-2)

dLNYUS_US1 $=$ LNYUS_US(-1)-LNYUS_US(-2), dLNMUS_MU1 = LNMUS_MU(-1)-LNMUS_MU(-2) $\mathrm{ecm} 1=1.0000 *$ LNUEX $+1.7988 *$ LNYUS_US $+.86717 * \bar{L}$ LNMS_MU 
Table 4

Vector Error Correction Estimates With Restrictions

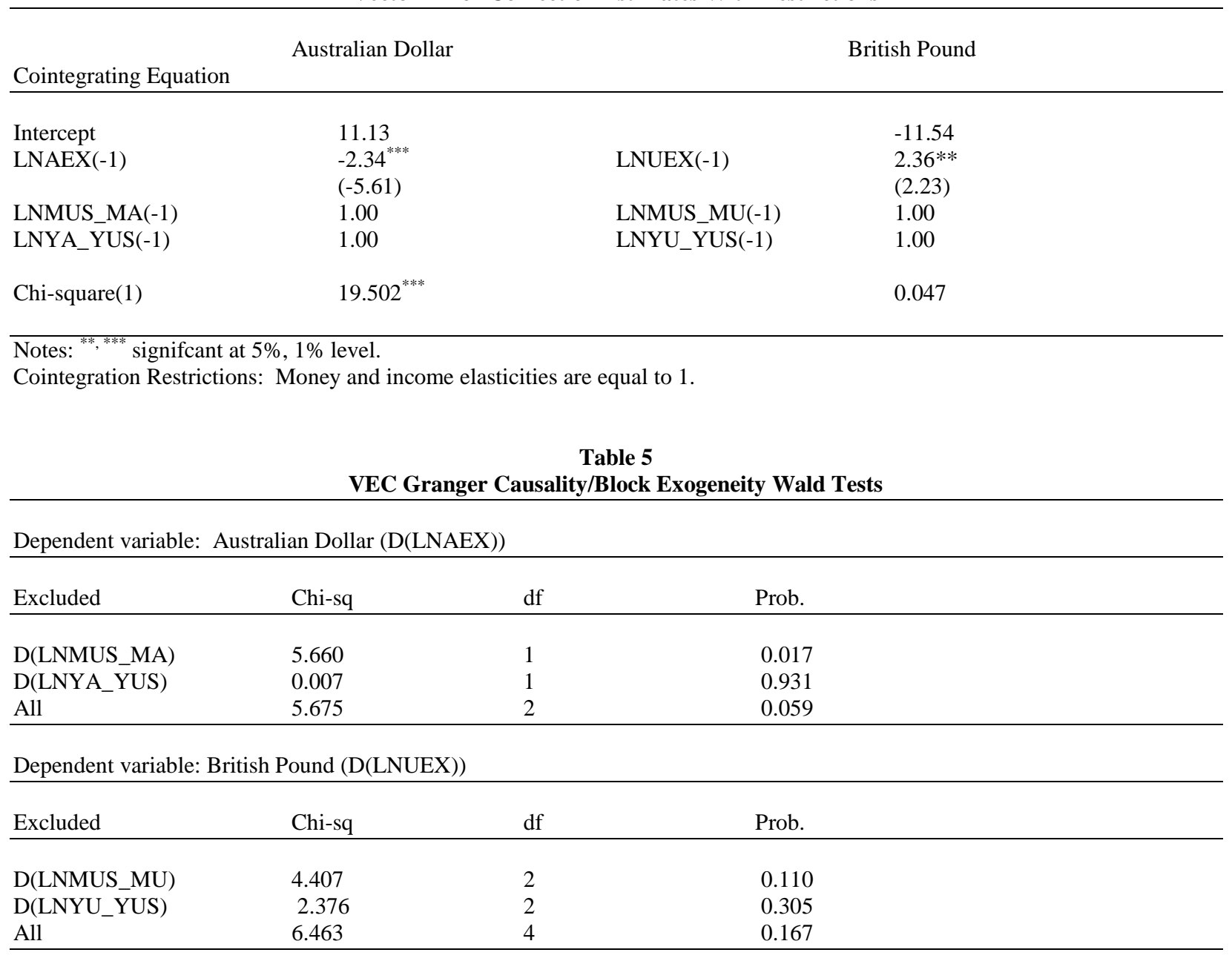


Panel A

Response of LNAEX to Cholesky

One S.D. Innovations

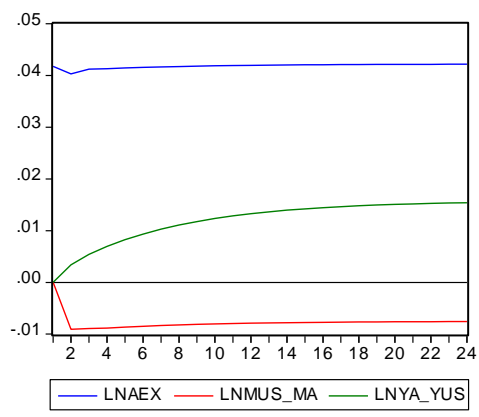

Response of LNMUS MA to Cholesky One S.D. Innovations

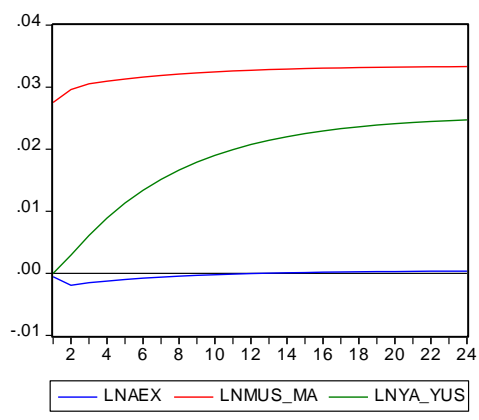

Response of LNYA_YUS to Cholesky One S.D. Innovations

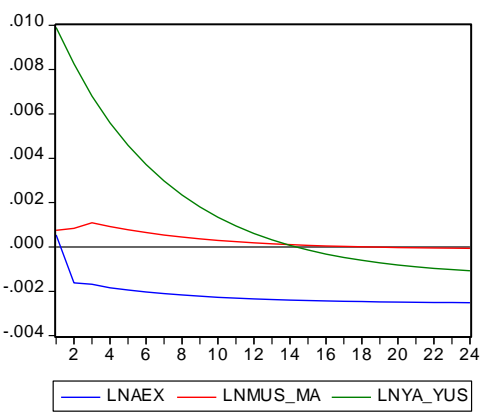

Figure 1

Panel B

Response of LNUEX to Cholesky

One S.D. Innovations

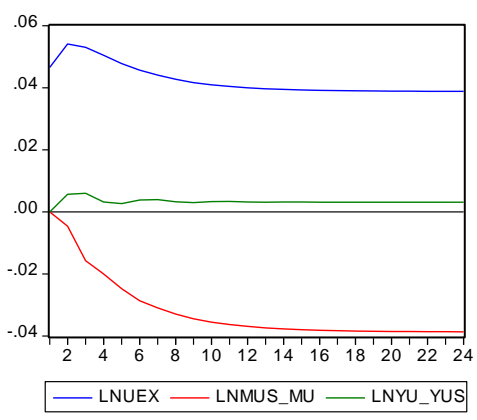

Response of LNMUS_MU to Cholesky One S.D. Innovations

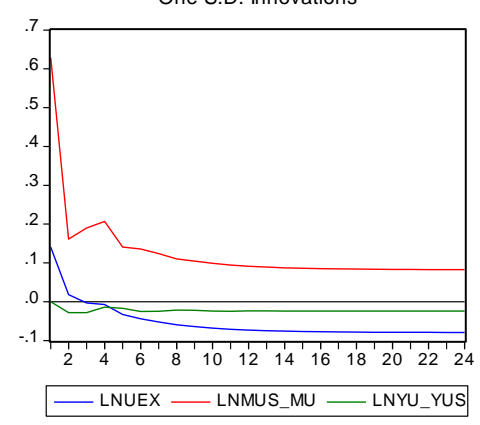

Response of LNYU_YUS to Cholesky One S.D. Innovations

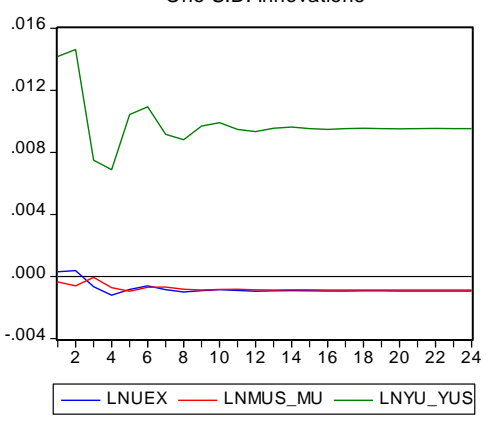


NOTES 